\title{
State-Dependent Interactions between Excitatory Neuromodulators in the Neuronal Control of Breathing
}

\author{
Atsushi Doi ${ }^{1,2}$ and Jan-Marino Ramirez ${ }^{1,2}$ \\ ${ }^{1}$ Center for Integrative Brain Research, Seattle Children's Research Institute, Seattle, Washington 98101, and 2Department of Neurological Surgery, \\ University of Washington School of Medicine, Seattle, Washington 98104
}

\begin{abstract}
All neuronal networks are modulated by multiple neuropeptides and biogenic amines. Yet, few studies investigate how different modulators interact to regulate network activity. Here we explored the state-dependent functional interactions between three excitatory neuromodulators acting on neurokinin1 (NK1), $\alpha 1$ noradrenergic $(\alpha 1 \mathrm{NE})$, and 5-HT2 serotonin receptors within the pre-Bötzinger complex (pre-BötC), an area critical for the generation of breathing. In anesthetized, in vivo mice, the reliance on endogenous NK1 activation depended on spontaneous breathing frequency and the modulatory state of the animal. Endogenous NK1 activation had no significant respiratory effect when stimulating raphe magnus and/or locus ceruleus, but became critical when $\alpha 1$ NE and 5-HT2 receptors were pharmacologically blocked. The dependence of the centrally generated respiratory rhythm on NK1 activation was blunted in the presence of $\alpha 1 \mathrm{NE}$ and 5-HT2 agonists as demonstrated in slices containing the pre-BötC. We conclude that a modulator's action is determined by the concurrent modulation and interaction with other neuromodulators. Deficiencies in one neuromodulator are immediately compensated by the action of other neuromodulators. This interplay could play a role in the state dependency of certain breathing disorders.
\end{abstract}

\section{Introduction}

Neuromodulators play critical roles in regulating every aspect of neuronal activity. Their functional roles are typically identified by using a variety of pharmacological and genetic approaches aimed at activating or blocking the action of a specific neuromodulator and characterizing the resulting functional consequences (Ptak et al., 2000, 2002; Peña and Ramirez, 2004; Duangdao et al., 2009; Hodges et al., 2009; Ward and Walker, 2009; Jansen et al., 2010). However, the functional outcome of a given manipulation, be it the activation or the deletion of a neuromodulator or ion channel, is often more complex than expected. This is most evident in genetically manipulated animals in which unexpected results are often attributed to compensatory mechanisms (Telgkamp et al., 2002; Hilaire et al., 2003; Swensen and Bean, 2005; Ortinski et al., 2006; Higuchi et al., 2008). The introduction of conditional gene knock-outs (Benavides et al., 2007; Djukic et al., 2007) or the recent development of approaches such as the use of allatostatin in genetically modified mammalian networks helped to overcome some of the difficulties in interpreting the potential influence of long-term compensatory mechanisms (Tan et al., 2008; Wehr et al., 2009; Zhou et al., 2009). However, a major conceptual problem in assessing the role of specific modulators or specific ion channels is the fact that

\footnotetext{
Received 0ct. 28, 2009; revised April 7, 2010; accepted April 27, 2010.

This study was supported by the National Institutes of Health (R01 HL/NS60120; P01 HL090554-01; R01 HL/ 68860). We thank Dr. Aguan Wei for his wonderful suggestions and editorial comments.

Correspondence should be addressed to either Dr. Atsushi Doi or Dr. Jan-Marino Ramirez, Center for Integrative Brain Research, Seattle Children's Research Institute, M/S C9S-10 1900 9th Avenue, Seattle, WA 98101. E-mail: atsushi.doi@seattlechildrens.org or nino.ramirez@seattlechildrens.org.

DOI:10.1523/JNEUROSCI.5361-09.2010

Copyright $\odot 2010$ the authors $\quad 0270-6474 / 10 / 308251-12 \$ 15.00 / 0$
}

neurons and networks are never controlled by single types of ion channels, receptors, and neuromodulators. Instead, neuronal activity is typically the result of a complex orchestration involving multiple ion channels, multiple receptors, and multiple neuropeptides and biogenic amines (Thoby-Brisson and Simmers, 1998; Doi and Ramirez, 2008; Grashow et al., 2009), and this orchestration is state dependent (Nadim et al., 2008). Thus, manipulating or lesioning a single type of ion channel, receptor, or neuromodulator will have unexpected effects, due to the interference with multiple regulatory systems and the state of the animal. In fact, it may be wrong to assume that any neuronal function depends on a single modulator, receptor, or ion channel. The multitude of regulatory processes is a fundamental biological property, and understanding how multiple receptors, ion channels, and neuromodulators are functionally integrated is of great basic scientific and clinical relevance.

Unfortunately, only a few studies directly investigate the role and interaction between different modulators and receptor subtypes (Peck et al., 2006; Stein et al., 2007; Fadok et al., 2009; Grashow et al., 2009). Here, we explored the converging influence of three excitatory neuromodulators on the mammalian respiratory network. The respiratory rhythm is generated within the ventrolateral side of the brainstem distributed between the pontine respiratory group, pre-Bötzinger complex (pre-BötC), and rostral ventral respiratory group (VRG) (Onimaru and Homma, 2003; Feldman and Del Negro, 2006; Smith et al., 2007). The pre-BötC is essential for generating rhythmic breathing activity (Achard et al., 2005), and is thought to play a role in generating different forms of inspiratory activities (Lieske et al., 2000).

Respiratory rhythm generation depends on classical neurotransmitters, such as amino acids, and acetylcholine, biogenic 
amines (Peña and Ramirez, 2002; Pagnotta et al., 2005; Shao and Feldman, 2005; Viemari and Ramirez, 2006), and neuropeptides (Bianchi et al., 1995). The release of these neuromodulators varies by awake/ sleep/anesthetized states (Dringenberg and Vanderwolf, 1998; Brown et al., 2001; Ursin, 2002; Berridge and Waterhouse, 2003). Here, we investigate the role of substance $\mathrm{P}$ (SP) in relation to norepinephrine and serotonin. Our study suggests that the relative contribution of these modulators depends on network state, and the state dependency of the network is partly determined by the interplay between these neuromodulators.

\section{Materials and Methods}

The transverse slice preparation

Brainstem transverse slice preparations from CD1 mice (P6-P10, Charles River Laboratories) were obtained using a technique described in detail previously (Ramirez et al., 1996). The most important steps are summarized here. Experimental procedures were approved by the Institutional Animal Care and Use at the Seattle Children's Research Institute. Mice were deeply anesthetized with ether and decapitated. Isolated brainstems were then placed in ice-cold artificial CSF (aCSF) bubbled with carbogen $\left(95 \% \mathrm{O}_{2}-5 \% \mathrm{CO}_{2}\right)$. The aCSF contained the following (in $\mathrm{mm}$ ): 128 $\mathrm{NaCl}, 3 \mathrm{KCl}, 1.5 \mathrm{CaCl}_{2}, 1 \mathrm{MgCl}_{2}, 24 \mathrm{NaHCO}_{3}$, $0.5 \mathrm{NaH}_{2} \mathrm{PO}_{4}$, and $30 \mathrm{D}$-glucose, $\mathrm{pH}$ 7.4. Brainstems were glued rostral end up onto an agar block for mounting into a vibratome (Leica Microsystems). Brainstems were serially sliced until the rostral boundary of the pre-BötC (Smith et al., 1991) was identified by anatomical landmarks such as disappearance of the facial nucleus, and the first appearance of the inferior olive, the nucleus ambiguous, and hypoglossal nucleus. A single 500- to $680-\mu \mathrm{m}$ thick slice was then taken. Because the slices also contained regions caudal to the pre-BötC, we refer to the region encompassed in the slice as the VRG. Slices were transferred into a recording chamber, continuously superfused with oxygenated aCSF, and maintained at a temperature of $30 \pm 0.5^{\circ} \mathrm{C}$. To initiate and maintain fictive respiratory rhythmic activity, the potassium concentration of the perfusate was raised from 3 to $8 \mathrm{~mm}$ over $30 \mathrm{~min}$ (Ramirez et al., 1996; Tryba et al., 2003).

In vivo anesthetized mouse preparation CD1 mice (P15-P23) were anesthetized with urethane $(1.5 \mathrm{~g} / \mathrm{kg})$. The electrical signal of the hypoglossal nerve and/or the electromyography (EMG) of intercostal muscles were recorded. Mice were placed in a supine position, and the head was fixed with a stereotaxic apparatus. The neck of the mice was opened from the ventral side, the trachea was cut, and plastic Y-shaped tubing for supplying oxygen was inserted into the proximal end of the trachea (cannulation). The bone of the skull covering the ventral brainstem was partially removed with small scissors and forceps. In this preparation, the reverse Y-shaped basilar
A



B

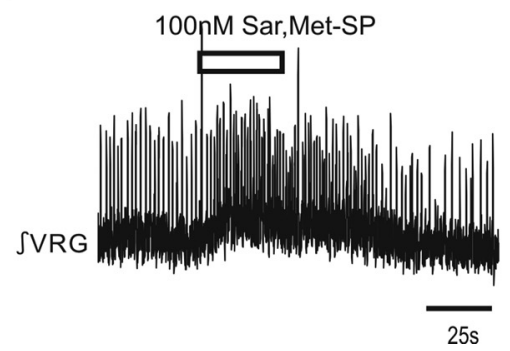

C
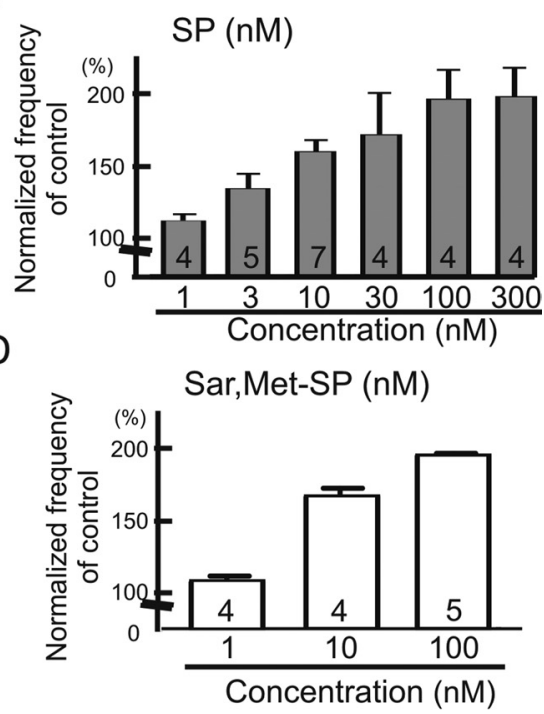

Figure 1. Exogenous application of either SP or NK1 agonist facilitates respiratory population activity recorded in medullary slice preparation containing the pre-BötC. Shown are effects of SP and NK1 agonist Sar,Met-SP on respiratory rhythmic activity recorded in a portion of the VRG containing the pre-BötC in vitro. $A, B$, Two traces of integrated activity obtained from extracellular population activity recorded from the surface of a portion of the VRG that contains the pre-BötC. Upward deflections reflect bursts of fictive inspiratory activity. Note that application of $30 \mathrm{~nm} \mathrm{SP}(\boldsymbol{A})$ and $100 \mathrm{~nm}$ Sar,Met-SP $(\boldsymbol{B})$ facilitates respiratory activity. $\boldsymbol{C}, \boldsymbol{D}$, Graphs indicating that SP $(\boldsymbol{C})$ and Sar,Met-SP (D) enhance respiratory rhythmic activity in a dose-dependent manner (collected number is shown in each bar graph).
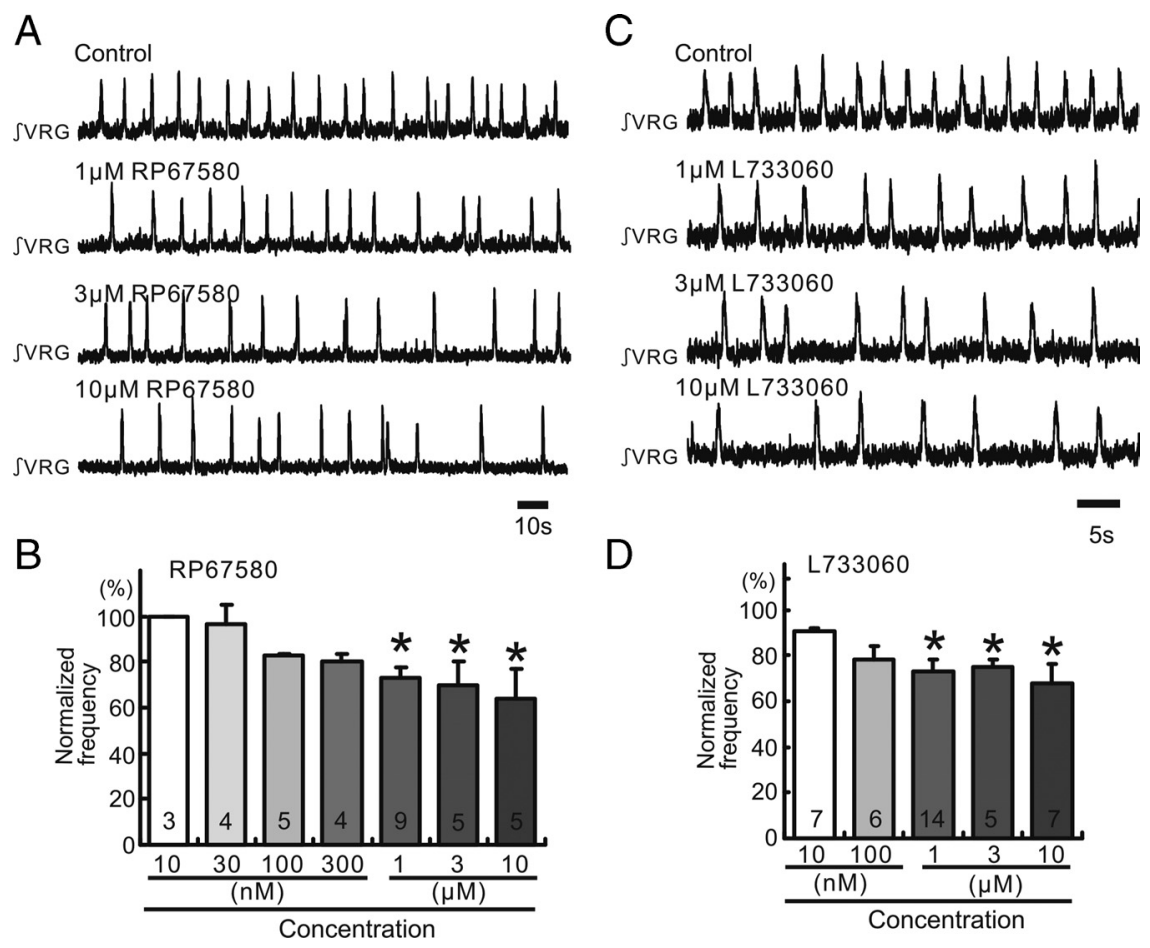

Figure 2. Endogenous SP release activates NK1 receptors in medullary slice preparation containing the pre-BötC. A, C, Integrated activity obtained from extracellular population activity recorded from the surface of a portion of the VRG containing the pre-BötC. Increasing concentrations of the NK1 antagonists RP67580 (A) and L733060 ( $C$ ) cause an increased inhibitory effect on rhythmic population activity (traces). $\boldsymbol{B}, \boldsymbol{D}$, Graphs indicating that RP67580 (B) and L733060 (D) inhibit the frequency of respiratory rhythmic activity (ordinate) in a dose-dependent manner (abscissa; ${ }^{*} p<0.05$, number is shown in each bar graph). The frequency values were normalized to the control frequency obtained before the application of the NK1 antagonists (100\%).

artery and the branches of the hypoglossal nerve could be observed. The dura and arachnoid membrane were removed to expose the ventral medulla. The surface of the ventral medulla was continuously perfused with $95 \% \mathrm{O}_{2}-5 \% \mathrm{CO}_{2}$ equilibrated aCSF solution at $30 \pm 0.5^{\circ} \mathrm{C}$. In all cases, 
$100 \%$ oxygen was supplied through cannulation without artificial ventilation.

\section{Electrical measurements}

Extracellular recordings. In the transverse slice preparation, population activity recordings were obtained with suction electrodes positioned on the surface of the ventrolateral region containing the pre-BötC. Signals were amplified $2000 \times$, filtered (low-pass, $1.5 \mathrm{kHz}$; high-pass, $250 \mathrm{~Hz}$ ), rectified, and integrated using an electronic filter (time constant of 30-50 $\mathrm{ms}$ ). Integrated population activity from the VRG was always in phase with integrated inspiratory activity of the hypoglossal motor nucleus (Telgkamp and Ramirez, 1999). All recordings were stored on a personal computer using pClamp software (version 9.2, Molecular Devices) and analyzed off-line using customized analysis software written with IGOR Pro and Mini Analysis (Wavemetrics and Synaptosoft) (Viemari and Ramirez, 2006). Burst amplitude, frequency, and duration were detected and calculated automatically and manually. An irregularity score was determined for each cycle by applying the following formula for consecutive cycle length value: $S_{n}=100 \times \operatorname{ABS}\left(P_{n}-P_{n-1}\right) / P_{n-1}$, where $S_{n}$ is the score of the $n$th cycle, $P_{n}$ is the period of the $n$th cycle, $P_{n-1}$ is the period of the cycle preceding the $n$th cycle, and ABS is the absolute value (Barthe and Clarac, 1997). Detected values were automatically sorted into tables that were imported into Excel and graphics programs (Corel Draw). These values were also used to analyze regularity of the VRG population.

Extracellular hypoglossal nerve or EMG recordings from intercostal muscles in anesthetized mice. A glass monopolar suction electrode (tip diameter 100-200 $\mu \mathrm{m}$ ) held in a micromanipulator was used to record from the hypoglossal nerve. Without cutting the hypoglossal nerve, the suction electrode was placed on the nerve. Extracellular signals were recorded using a patch-clamp amplifier (HEKA EPC8, HEKA Electronic). A Teflon-covered Ag bipolar electrode was used for EMG recordings. The skin over the abdominal and intercostal area on the right side was partially removed, and the bipolar electrode was placed on the surface of the intercostal muscle. Signals were AC amplified and bandpass filtered (8 $\mathrm{Hz}$ to $3 \mathrm{kHz}$ )

Electrical stimulation of raphe magnus and locus ceruleus. After mice were full anesthetized and immobilized, concentric bipolar stimulation electrodes (TM53CCINS, World Precision Instruments) were inserted into both raphe magnus (RM) and locus ceruleus (LC) from the ventral side of the medulla. Electrical stimulation for both nuclei used repetitive rectangular pulses (duration, $1 \mathrm{~ms}$; intensity, $10-100 \mu \mathrm{A}$ ). Because of the large electrical stimulus artifacts created while RM and/or the LC were stimulated, it was impossible to record activity from the hypoglossal nerve during electrical stimulation. EMG activity was very stable and much less affected by the artifacts caused by electrical stimulation. We therefore recorded EMG from intercostal muscle as a measure of breathing activity for these stimulation experiments.

\section{Drug application}

Slice preparation. In slice preparations, a perfusion system was used that allowed rapid drug applications within $5 \mathrm{~s}$, using a modification of the "Y-tube technique" (Murase et al., 1990). The Y-tube technique uses both negative vacuum pressure and gravity. The Y-shaped tube is created from polyethylene tubing bent into a $\mathrm{V}$ shape, with a small hole made at the curve end, into which a short segment of thinner polyethylene tubing was inserted and affixed with silicon-based glue, forming the tip of the Y-tube. One end of the V-shaped tubing was connected to the test aCSF reservoir by silicon tubing. Separate control and test solution reservoirs were held $50 \mathrm{~cm}$ above the level of the Y-tube tip, so that solution flowed from the Y-tube tip by gravity. The other end of the $\mathrm{V}$-shaped tubing was connected to a drain bottle through an electrical valve (Series 075T, Bio-Chem). Constant negative pressure (6.77 psi) was maintained in the drain bottle by the vacuum pump (VPO435A, MEDO USA). Closing the valve to the drain bottle allowed the flow of perfusate by gravity $(10 \mathrm{ml} / 3$ $\min$ ), whereas opening the valve closed this flow. The system was used as follows. The tip of the Y-tube was positioned at a distance 1-2 $\mathrm{mm}$ from the pre-BötC. For control perfusions, the input end of the Y-tubing was placed in the control aCSF reservoir, with the drain valve closed. To apply
A

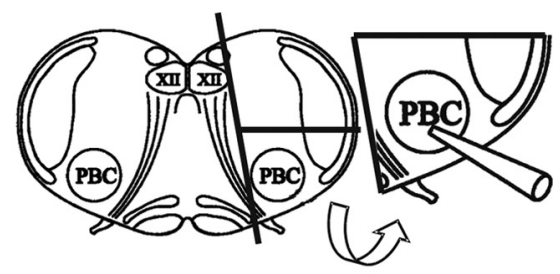

B


C
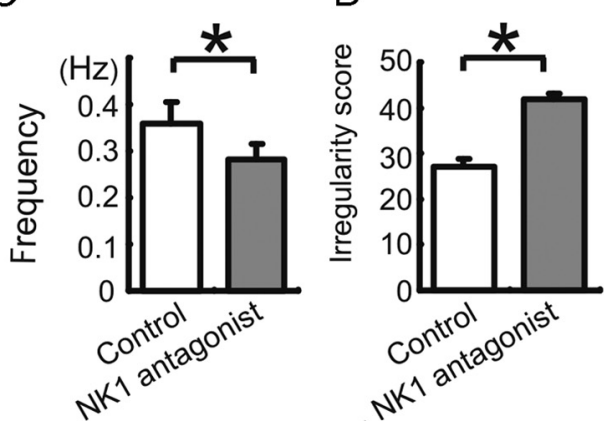

Figure 3. Endogenous SP activation persists in pre-BötC island preparation. Shown is the effect of the NK1 antagonist on respiratory population activity recorded from a pre-BötC island slice. $\boldsymbol{A}$, Schematic of a transverse slice (left schematic), which is used to isolate an island slice (right schematic) that contains the pre-BötC and a minimal amount of surrounding tissue. $B$, Integrated population activity obtained from extracellular activity recorded from the surface of a portion of the VRG containing the pre-BötC under control conditions (top trace) and following the application of the NK1 antagonist RP67580 (bottom trace). C, D, The application of the NK1 antagonist RP67580 decreases significantly the frequency $(C)$ and increases the irregularity of respiratory rhythmic activity (D). The irregularity is expressed as the "irregularity score" as

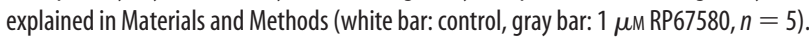

drugs, the input end of the Y-tubing was removed from the control aCSF reservoir, wiped on tissue paper, and transferred to the test aCSF reservoir. The difference of temperature between control and test aCSF was measured to be constant within $\pm 0.3^{\circ} \mathrm{C}$

Microinjection studies in in vivo anesthetized mice. Microsyringes (Hamilton microsyringe no. 80330) with 33 gauge needles containing neurokinin1 (NK1) receptor antagonist (100 $\mu \mathrm{M}$ RP67580, $1 \mu \mathrm{l}), \alpha 1$ noradrenergic $(\alpha 1 \mathrm{NE})$ receptor antagonist ( $60 \mu \mathrm{M}$ prazosin, $0.5 \mu \mathrm{l})$, or cocktail of NE receptor antagonist ( $\alpha 1 \mathrm{NE}$ antagonist $30 \mu \mathrm{M}$ prazosin, $\alpha 2$ $\mathrm{NE}$ antagonist $1 \mu \mathrm{M}$ yohimbine, $\beta \mathrm{NE}$ antagonist $30 \mu \mathrm{M}$ alprenolol, total $0.6 \mu \mathrm{l}$ ) and/or 5-HT2 serotonin receptor antagonist (ketanserin $80 \mu \mathrm{M}$, $0.5 \mu \mathrm{l}$ ) were positioned with micromanipulators (KITE, World Precision Instruments). The needles of the microsyringes were inserted into the right pre-BötC from the ventral side. During hypoglossal nerve recording or intercostal EMG recordings, these antagonists were microinjected into the right pre-BötC at a rate of $0.3 \mu \mathrm{l} / \mathrm{min}$. We did not attempt to perform bilateral needle injections to limit the damage to the pre-BötC, which would have compromised respiratory rhythm-generating mechanisms.

Identification of drug injection and electrical stimulation sites in in vivo preparations. Anodal electrolytic lesions were made by DC currents (500 $\mu \mathrm{A}$ ) to mark the stimulation sites. Evans blue (Sigma $0.1 \mu \mathrm{l}$ ) was injected 
into the pre-BötC to label NK1 antagonist injection sites. After electrophysiological recordings were completed, mice were deeply anesthetized with supplemental urethane. Then, transcardial perfusions with $4 \%$ paraformaldehyde (PFA) in $0.1 \mathrm{~m}$ PBS, pH 7.4, were performed. The medulla was removed and immersed overnight in 4\% PFA with $30 \%$ sucrose. The medulla was subsequently cut into $50 \mu \mathrm{m}$ sections on a cryostat and stained with cresyl violet.

\section{Drugs}

The following drugs were used in this study: SP (Tocris Cookson), $\left[\operatorname{Sar}^{9}, \operatorname{Met}\left(\mathrm{O}_{2}\right)^{11}\right]-\mathrm{SP}$ (Sar,Met-SP, Tocris Cookson), ( $3 \mathrm{a} R, 7 \mathrm{a} R)$ octahydro-2-[1-imino-2-(2-methoxyphenyl) ethyl]-7,7-diphenyl-4 $\mathrm{H}$-isoindol (RP67580, Tocris Cookson), GR82334 (Tocris Cookson), (2S,3S)-3-[[3,5-bis(trifluoromethyl)phenyl] methoxy]-2-phenylpiperidine hydrochloride (L733060, Tocris Cookson), $N$-acetyl-L-tryptophan 3,5-bis(trifluoromethyl)benzyl ester (L732138, Tocris Cookson), 1-(4-amino-6, 7-dimethoxy-2-quinazolinyl)-4-(2-furanylcarbonyl)piperazine hydrochloride (prazosin, Tocris Cookson), 3-(2-[4-(4-fluorobenzoyl)1-piperidinyl (ketanserin, Sigma-RBI), 1-(o-allylphenoxy)-3-(isopropylamino)-2propanol hydrochloride (alprenolol, SigmaRBI), 2-[(2-cyclopropylphenoxy)methyl]-4, 5-dihydro- $1 \mathrm{H}$-imidazole hydrochloride (cirazoline hydrochloride, Sigma-RBI), and ( \pm )-1(2,5-dimethoxy-4-iodophenyl)-2-amino propane hydrochloride (DOI hydrochloride, Sigma-RBI).

All drugs were initially dissolved in dimethylsulfoxide (DMSO, Sigma-RBI) or distilled water and were mixed to final concentrations in aCSF. The final concentration of DMSO was $<0.3 \%$ in the aCSF.

\section{Statistical analysis}

Data were analyzed with SPSS and StatView software (SPSS 8.0) and StatView-J5.0 (Adept Scientific). Burst frequency and irregularity score were assessed by Wilcoxon signed-rank test as a paired nonparametric statistical test. The Mann-Whitney $U$ test was used for unpaired nonparametric statistical analysis. In other cases, a one-way ANOVA was used for repeated measurements on the same subjects, followed by Tukey's or Bonferroni tests for multiple-comparison analysis. Statistical significance was assumed to be significant if $p<0.05$. Deviations from the mean are given in SE.

\section{Results}

\section{Endogenous SP release consistently activates respiratory} activity in slice preparations containing the pre-BötC

The endogenous SP release and tonic NK1 receptor activation were characterized in isolated transverse slice preparations containing the pre-BötC. SP and the NK1 agonist Sar,Met-SP increased extracellularly recorded rhythmic population activity in a dose-dependent manner (Fig. 1), while NK1 receptor-specific antagonists RP67580, L733060, L732138, and GR82334 produced an inhibitory effect on respiratory frequency in a dosedependent manner (Fig. 2; supplemental Fig. 1, available at www. jneurosci.org as supplemental material). The inhibitory effects of RP67580 on population activity was confirmed in reduced preBötC island preparations (Fig. 3), suggesting that the source for endogenous SP release is contained within the pre-BötC region. $\left.R^{2}=0.11\right)$.

\section{Frequency}
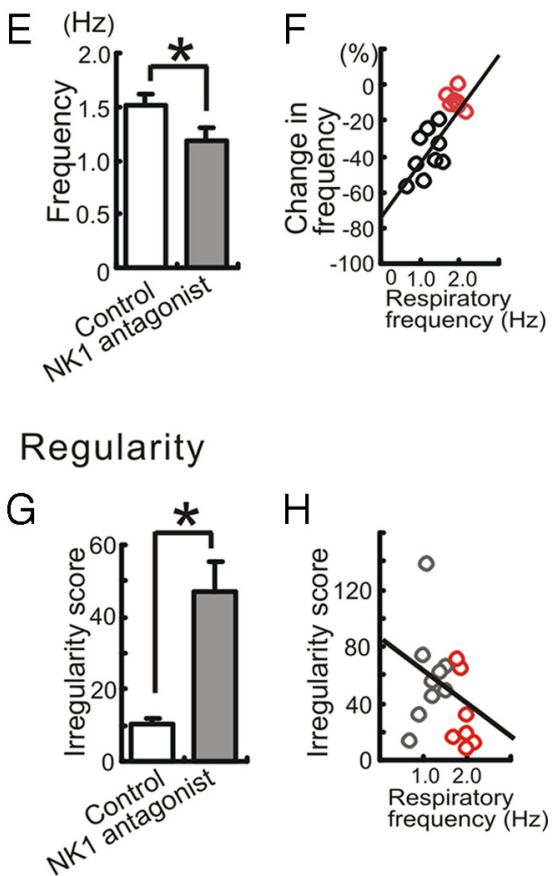

$\mathrm{H}$

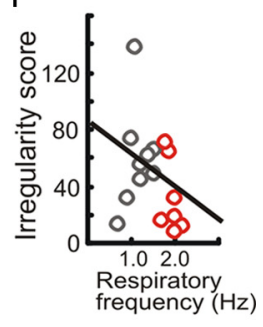

Figure 4. The inhibitory effect of NK1 antagonist on respiratory activity depends on the breathing frequency in the anesthetized animal. Shown is the effect of NK1 antagonist on respiratory activity in in vivo mice. $A$, Left, Identification of the injection site by Evans blue, which was injected together with the NK1 antagonist. Right, The tract of a single needle that was inserted into the

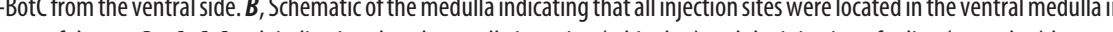
(he percentage change in respiratory frequency describes the percentage frequency decrease caused by the NK injection of NK1 antagonist increases the irregularity score $\left({ }^{*} p<0.05\right)$. $\boldsymbol{H}$, Scatter plot illustrates that there is no significant relationship between the irregularity score (ordinate) and the baseline respiratory frequency (abscissa) $(y=-24.4 x-83.5$,

Inhibition of respiratory rhythm by NK1 antagonist in hemilateral pre-BötC depends on the breathing rate in anesthetized whole animals

We next investigated the effects of endogenous NK1 receptor activation within the pre-BötC on spontaneous breathing rhythms using anesthetized in vivo mice. In a series of experiments, we directly delivered the specific NK1 antagonist RP67580 by focal hemilateral injection into the pre-BötC region (Fig. $4 A, B)$, while monitoring respiration in a hypoglossal nerve recording. Control needle insertions and aCSF injections $(1 \mu \mathrm{l})$ into the right pre-BötC had no significant effect on respiratory activity (Fig. 4C). Injection of the NK1 antagonist RP67580 (100 $\mu \mathrm{M}, 1 \mu \mathrm{l})$ in the same location significantly decreased both the rate (Fig. $4 D, E$; supplemental Fig. 2, available at www.jneurosci. org as supplemental material) and regularity (Fig. $4 G$ ) of respiratory rhythm. However, in contrast to the in vitro experiments, the effect on the respiratory rhythm was not as consistent, and we observed that blocking NK1 receptor had striking effects in some, but not all, animals. Indeed, we found a significant correlation between the degree of inhibition on respiratory rate and initial breathing rate (Fig. $4 F$ ). This effect was most notable for slow initial breathing rates less than $2 \mathrm{~Hz}$. We observed no significant correlation between NK1 antagonist-dependent decreases in ir- 
A
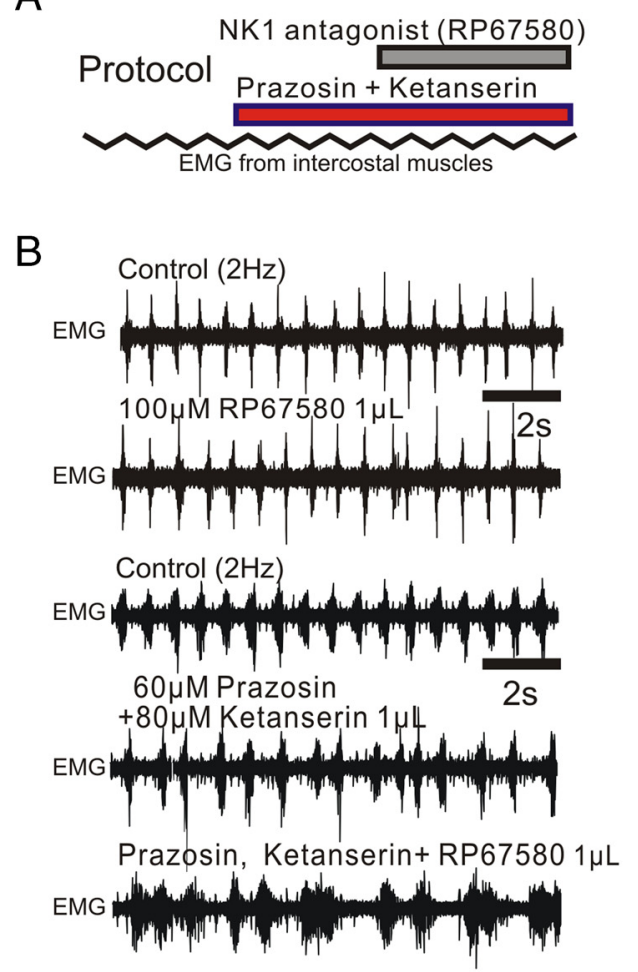

C

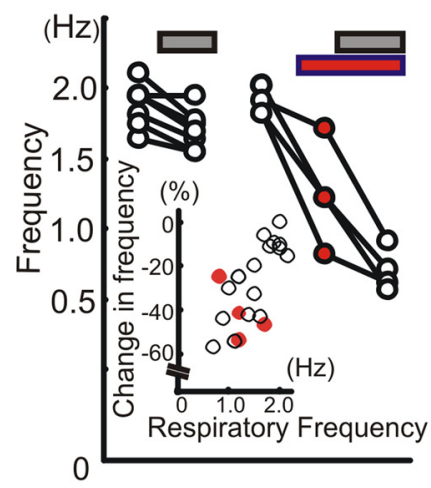

D

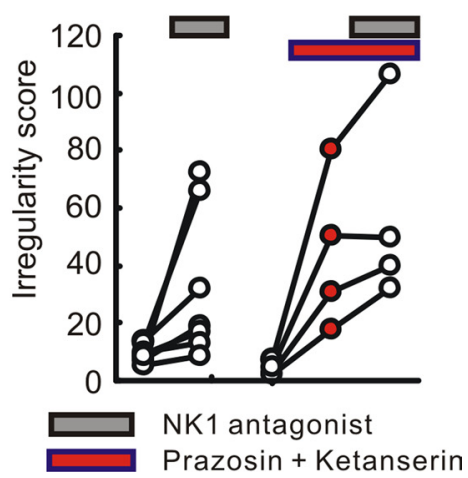

Figure 5. The modulatory role of NK1 receptors depends on the activation of $\alpha 1$ NE and 5-HT2 receptors. $\boldsymbol{A}$, Schematic illustrating the experimental protocol used for examining the relationship between NK1, $\alpha 1$ NE, and 5-HT2 receptors. $\boldsymbol{B}$, EMG activity recorded from intercostal muscles under control conditions (top trace), following the injection of the NK1 antagonist (RP67580, second trace), control conditions of the other case (third trace), following the injection of a cocktail containing prazosin and ketanserin (fourth trace), and following the additional injection of the NK1 antagonist (bottom trace). $\boldsymbol{C}, \boldsymbol{D}$, The effects of the NK1 antagonist (gray bars) on respiratory frequency $(\boldsymbol{C})$ and irregularity score $(\boldsymbol{D})$ of the respiratory frequency are enhanced following the concurrent injection of $\alpha 1 \mathrm{NE}$ and 5-HT2 antagonists (red bars). The inset in Cillustrates that blocking both $\alpha 1 \mathrm{NE}$ and $5-\mathrm{HT} 2$ receptors decreases the respiratory frequency, indicated as a negative percentage change (red dots).

regularity score and initial breathing rate (Fig. $4 H$ ). We hypothesize that spontaneous breathing rates of $\sim 2 \mathrm{~Hz}$ and those below $2 \mathrm{~Hz}$ reflect different modulatory states of the respiratory network, determined by other excitatory neuromodulators.

To address this hypothesis, we manipulated the modulatory state of the respiratory network using various pharmacological and electrophysiological approaches targeted at the pre-BötC.

In one series of experiments, we only used anesthetized mice with an initial spontaneous respiratory rate of $2 \mathrm{~Hz}$. Before injecting NK1 antagonist into the pre-BötC, we preinjected antagonists of both $\alpha 1 \mathrm{NE}$ receptors (prazosin, $60 \mu \mathrm{M}, 0.5 \mu \mathrm{l}$ ), and 5-HT2 receptors (ketanserin, $80 \mu \mathrm{M}, 0.5 \mu \mathrm{l}$ ) into the same hemilateral site in the pre-BötC (Fig. 5A,B). The combined injection of both prazosin and ketanserin decreased both the frequency and regularity of respiratory rhythms. These results suggest that tonic activation of both $\alpha 1 \mathrm{NE}$ receptors and 5-HT2 receptors within the pre-BötC is required for the maintenance of both high respiratory frequency and regularity. In the absence of tonic $\alpha 1$ NE and 5-HT2 receptor activation, subsequent injection of NK1 receptor antagonist further reduced respiratory rate (Fig. $5 B-D$ ). This shows that endogenous activation of NK1 receptors becomes critical for respiratory rhythm generation when $\alpha 1 \mathrm{NE}$ and 5-HT2 receptor activation is decreased and baseline respiratory rate is low.
Electrical stimulation of LC and RM blocks the effect of NK1 receptor antagonist

We next performed ipsilateral electrical stimulation of LC and RM in combination with hemilateral injection of NK1 antagonist within the pre-BötC in semi-intact mice to investigate how increased aminergic drive influences the dependency on endogenous NK1 activation. In the CNS, the $\mathrm{LC}$ and RM provide the main sources for NE and 5-HT, respectively (Mason, 2001; VanderHorst and Ulfhake, 2006). Both these nuclei provide strong projections to the pre-BötC (Bianchi et al., 1995). Under control conditions, electrical stimulation of either LC or RM increased the frequency of the breathing activity, in an intensity-dependent manner (Fig. $6 A-C$, electrical stimulation for $10 \mathrm{~s})$. Electrical stimulation-induced facilitation of respiration was acute and reversible, suggesting that the effect was due to the neuronal stimulation and not due to a collateral structural damage (Fig. $6 D$ ). In all of the five examined cases, the actual increase in breathing rate caused by the simultaneous LC and RM stimulation was smaller than the sum of the rate increases expected from the experiments in which LC and RM were stimulated separately (Fig. $6 E$ ).

After injection of the NK1 receptor antagonist into the pre-BötC (Fig. 7D, second trace), electrical stimulation of either LC or RM nuclei facilitated the respiratory rhythm (Fig. $7 D$, third and fourth traces).

The respiratory frequency reduced by the NK1 receptor antagonist returned to control levels following stimulation of LC and/or RM (Fig. 8A, B, D, E,G,H). Stimulation of LC and/or RM significantly reduced also the breathing irregularity caused by the NK1 antagonist. However, the regularity of the respiratory rhythm did not fully return to control levels (Fig. 8C, $F, I$ ).

\section{Electrical stimulation of LC induces endogenous release of $\mathrm{NE}$ and acts on NE receptors presumably in the pre-BötC}

To investigate the mechanisms underlying the facilitation of the respiratory rhythm by LC electrical stimulation (Fig. 6), we compared the increase of the respiratory frequency in the presence and absence of NE receptor antagonists. The cocktail injection of NE receptor antagonists ( $\alpha 1 \mathrm{NE}$ antagonist prazosin $30 \mu \mathrm{M}, \alpha 2$ $\mathrm{NE}$ antagonist yohimbine $1 \mu \mathrm{M}$, and $\beta \mathrm{NE}$ antagonist alprenolol $30 \mu \mathrm{M}$, total $0.6 \mu \mathrm{l}$ ) into the hemilateral pre-BötC decreased the frequency and increased the irregularity score (Fig. $9 A, D, E,{ }^{*} p<$ $0.05, n=5)$. Under this condition, further LC stimulation enhanced the respiratory frequency (Fig. 9B). However, the facilitation induced by LC electrical stimulation in the presence of NE antagonists was significantly lower than the facilitation induced in the absence of NE antagonists (Fig. $9 F,{ }^{*} p<0.05, n=5$ ). These results suggest that tonic activation of $\alpha 1, \alpha 2$, and $\beta \mathrm{NE}$ receptors contributes to an increase in respiratory frequency and regularity, that LC stimulation induces endogenous release of NE, and that 
the endogenous NE release seems to activate NE receptors within the pre-BötC.

\section{Electrical stimulation of RM facilitates endogenous release of 5-HT and activates 5-HT2 receptor in the pre-BötC}

To explore the mechanisms underlying the increase of the respiratory rhythm by RM electrical stimulation (Fig. 6), we compared the RM-induced frequency increase in the absence and presence of a 5-HT2 receptor antagonist. The injection of the 5-HT2 receptor antagonist ketanserin $(80 \mu \mathrm{M}, 0.6 \mu \mathrm{l})$ into the hemilateral pre-BötC decreased the frequency, but did not significantly increase the irregularity score (Fig. $10 A, D, E,{ }^{\star} p<0.05, n=$ $8)$. Under these conditions, further RM stimulation enhanced the respiratory frequency (Fig. 10B). However, the RMevoked respiratory facilitation in the presence of the 5-HT2 receptor antagonist was significantly lower than the facilitation evoked in the absence of the antagonist (Fig. $10 F,{ }^{*} p<0.05, n=8$ ). These results suggest that tonic activation of 5-HT2 receptor increases respiratory rhythm, that RM stimulation induces the endogenous release of $5-\mathrm{HT}$, and that endogenous 5-HT release seems to activate 5-HT2 receptors within the pre-BötC.

\section{Activation of $\alpha 1$ NE receptors or 5-HT2 receptors masks the inhibitory effect of NK1 antagonists on respiratory activity in the slice preparation}

Our in vivo data suggested that the modulation of respiratory frequency by endogenous NK1 receptor activation is dependent on the interaction with $\alpha 1 \mathrm{NE}$ and 5-HT2 receptors (Fig. 5). We next examined whether this is also the case under in vitro conditions. We pharmacologically manipulated these receptors using the NK1 receptor antagonist L733060, the $\alpha 1$ NE receptor agonist cirazoline, and the 5-HT2 receptor agonist DOI. Pretreatment with any of these drugs suppressed the inhibitory effects of the NK1 antagonist ( $3 \mu \mathrm{M}$ L733060) on frequency and regularity of the respiratory rhythm (Fig. $11 B, C)(\mathrm{ns}, n=5)$. These results suggest that, also in the reduced slice preparation, the activation of $\alpha 1 \mathrm{NE}$ and 5-HT2 receptors can mask the effects of endogenous NK1 receptor activation.

\section{Discussion}

Our study indicates that the dependency of the respiratory rhythm on endogenous SP release and tonic NK1 receptor activation is partly determined by the interaction with other excitatory neuromodulators. Respiration depends on endogenous NK1 receptor activation only at low breathing frequency $(<1.5 \mathrm{~Hz})$ or at decreased $\alpha 1 \mathrm{NE}$ and/or 5-HT2 receptor activation. At high breathing rates $(\sim 2 \mathrm{~Hz})$ or when locus ceruleus or raphe magnus are stimulated, NK1 activation is not essential for regulating breathing frequency.

However, it must be emphasized that respiratory rhythm generation will depend also on numerous other neuromodulators. Endogenously released NE from the A5 region and LC bind both
B $\quad$ C

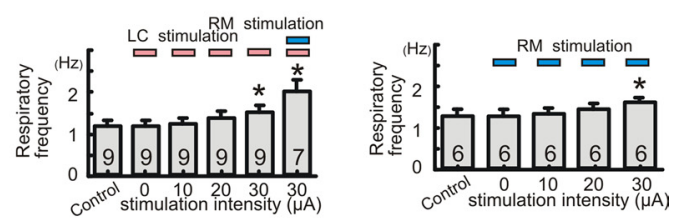

D
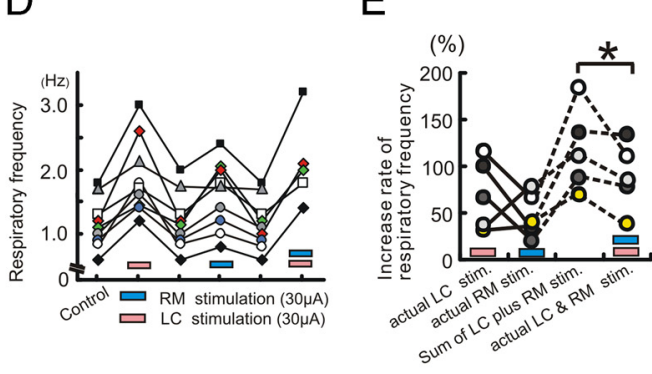

Figure 6. Electrical stimulation of LC or RM facilitates respiratory activity in an intensity-dependent manner. $\boldsymbol{A}$, EMG activity (blue bar), the sum calculated from the sum of each of these separate stimulations, and the actual increase d by the simultaneous stimulation of $L C$ and RM. Each dot represents a stimulation experiment. Experiments conducted in the

$\alpha 1$ and $\alpha 2$ NE receptors that contribute to respiratory rhythm generation (Hilaire et al., 2004). These nuclei also contain acetylcholine acting on M3 ACh receptors in the pre-BötC (Shao and Feldman, 2005). Serotonin released from RM will also activate 5-HT4 and 5-HT7 receptors known to exert $\mathrm{G}_{\mathrm{s}}$ protein-mediated excitatory effects on the respiratory rhythm (Manzke et al., 2003; Kvachnina et al., 2005). RM stimulation might also release CCK and TRH (Ellenberger and Smith, 1999; Hodges and Richerson, 2008). Moreover, orexin originating from hypothalamus might enhance LC and RM activity (Bernard et al., 2003; Tao et al., 2006; Dias et al., 2010). Thus, it is likely that these and many other yet unidentified modulatory actions will contribute to respiratory rhythm generation. To appreciate the complexity of neuromodulation, it is insightful to learn from the elegant studies performed in a small crustacean neuronal network (Nusbaum, 2002; Thirumalai and Marder, 2002; Birmingham et al., 2003; Peck et al., 2006).

We focused on the concurrent modulation of NK1, $\alpha 1 \mathrm{NE}$, and 5-HT2 receptors, because all three receptors presumably act on $\mathrm{G}_{\mathrm{q} / 11}$ proteins, and possibly converge on common downstream targeted channels. Here, we demonstrated that stimulating LC and RM facilitates release of NE and 5-HT, respectively. These neuromodulators bind to NE and 5-HT2 receptors within the pre-BötC (Figs. 9, 10). The effects caused by stimulating LC and RM were not additive (Fig. $6 E$ ), suggesting the involvement of common downstream targets. These targets could include, e.g., TRPM4/5 (Crowder et al., 2007), TRPC3/7 (Ben-Mabrouk and Tryba, 2010), NALCN (leak $\mathrm{Na}^{+}$) (Lu et al., 2009), and TASK (leak $\mathrm{K}^{+}$) channels (Hodges and Richerson, 2008).

The localization and physiological and pharmacological properties of NK1 receptors in the pre-BötC are well established, and 
A

Electrostimulation of nuclei

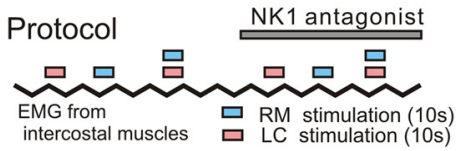

B


C

\section{RM stimulation site}

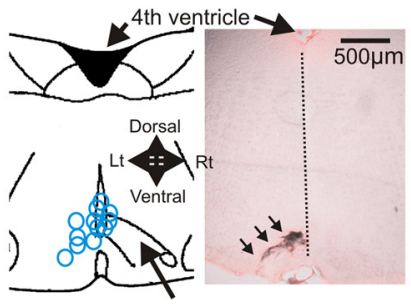

RM

Figure 7. Electrostimulation of LC or RM blunts inhibitory effects of NK1 receptors. $\boldsymbol{A}$, Schematic illustrating the experimenta protocol for the electrical stimulation of LC (pink bars) and RM (blue bars) in the absence and presence of NK1 antagonist (gray bar). $\boldsymbol{B}, \boldsymbol{C}$, Stimulation sites of $L C$ ( $\boldsymbol{B}$, pink circles) and RM ( $\boldsymbol{C}$, blue circles) were labeled at the end of each experiment by injecting a high current amplitude into the stimulation electrode (anatomical labeling is indicated by arrows in the histological sections shown in $\boldsymbol{B}$ and C. D, EMG activity obtained from intercostal muscles under control conditions (top trace), during the injection of the NK1 antagonist (second trace), during electrical stimulation of LC while injecting the NK1 antagonist (third trace), and during RM electrical stimulation while injecting the NK1 antagonist (bottom trace).

NK1 receptor abundance defines the pre-BötC (Gray et al., 1999; Guyenet et al., 2002; Liu et al., 2004; Morgado-Valle and Feldman, 2004; Hayes and Del Negro, 2007; Fong and Potts, 2008). However, in the brainstem SP and NK1 receptors are also expressed in the nucleus of solitary tracts (NTS), raphe nucleus, and nucleus ambiguus (Colin et al., 2002; Guyenet et al., 2002; Léger et al., 2002). These nuclei have connections within the VRG, which includes the pre-BötC (Bianchi et al., 1995; Zec and Kinney, 2003). To reduce the possibility of endogenous SP diffusing from NTS and raphe, we characterized the NK1 effects also in pre-BötC island preparations (Fig. 3). Although, suggestive for a direct pre-BötC effect, SP may be released also from SP-containing active presynaptic terminals from areas including NTS, raphe, or nucleus ambiguus (Guyenet et al., 2002). This applies not only to the island but to all in vitro slices regardless of size and thickness; presynaptic terminals from other areas may still be active and effective. Thus, we cannot exclude the possibility that some effects caused in this study (in vivo and in vitro) were mediated by areas other than the pre-BötC.

Blocking endogenous NK1 activation affected respiratory frequency and regularity. The frequency decreased by $\sim 30 \%$ in response to NK1 antagonists, suggesting that endogenous NK1 activation contributes only partly to the regulation of the respi- ratory frequency. LC and RM stimulation was capable of restoring the respiratory frequency and also reducing respiratory irregularity in vivo. But, some irregularity remained. By contrast, exogenously applied $\alpha 1 \mathrm{NE}$ and 5-HT2 agonists were capable of fully restoring respiratory frequency and regularity in vitro. A possible explanation is that LC and RM stimulation caused more complex modulatory effects and the release of different modulators that together could partly oppose the full recovery of the regularity. It could also be that the electrical stimulation of LC and RM was not sufficiently strong to cause sufficient neuromodulator release to fully compensate for the irregularity. However, to avoid unspecific effects, we did not attempt to further increase the current injected into LC and RM. Hence some irregularity remained in the stimulation experiments, while the pharmacological application of specific agonists in the more reduced in vitro network sufficed to fully restore frequency and regularity.

Although, pacemaker and nonpacemaker neurons were not intracellularly recorded in the present study, it is known that substance P (Peña and Ramirez, 2004), serotonin (Peña and Ramirez, 2002), and NE (Viemari and Ramirez, 2006) endogenously modulate respiratory neurons and differentially alter two types of bursting mechanisms described within the preBötzinger complex: bursting that depends on the activation of the calcium-activated nonspecific cation current $\left(I_{\mathrm{CAN}}, \mathrm{TRPM} 4,5\right)$ (Peña et al., 2004; Crowder et al., 2007) and bursting that relies on the persistent sodium current $\left(I_{\mathrm{Nap}}\right)$ (Del Negro et al., 2002; Peña et al., 2004). These inward currents as well as some outward currents such as the TASK channel are present not only in pacemaker neurons, but also in many nonpacemaker neurons and are thought to contribute to the amplification of synaptic transmission and rhythm generation (Ramirez et al., 1996; Del Negro et al., 2002; Crowder et al., 2007; Koizumi et al., 2010). Following blockade of $I_{\mathrm{Nap}}$ with riluzole, NE causes irregularities and a breakdown of respiratory rhythm generation. By contrast, the respiratory rhythm remains stable following blockade of $I_{\mathrm{CAN}}$ (Viemari and Ramirez, 2006). This finding suggests that $I_{\text {Nap }}$ is critical for the modulatory effect on the regularity of the respiratory rhythm. Given that $I_{\mathrm{Nap}}$-dependent bursting is also modulated by $\mathrm{NK} 1$ and 5-HT2A receptor activation (Peña and Ramirez, 2002, 2004; Ramirez et al., 2004), this mechanism could be involved in some of the modulatory effects described in the present study. However, to substantiate this hypothesis, further studies will be necessary that specifically address the convergent endogenous modulation of respiratory nonpacemakers, pacemakers, and their bursting mechanisms. But, it is important to emphasize that the modulatory effects described in the present study are likely more complex.

The electrical stimulation of LC and RM will also activate fibers of passage. Moreover, neurons in LC and RM release not 
only NE and serotonin, but also other neuromodulators that are colocalized in these neurons. Serotonergic neurons from raphe pallidus, raphe magnus, and raphe obscurus project to the pre-BötC (Paterson et al., 2009), and serotonin colocalizes with SP in presynaptic terminals within the pre-BötC (Hodges and Richerson, 2008; Ptak et al., 2009). 5-HT- and SPcontaining neurons in raphe obscurus project and excite neurons in the preBötC (Ptak et al., 2009). Indeed, large proportions of 5-HT cell bodies in the raphe region of the lower medulla contain SP (Hökfelt et al., 2000). Thus, if both 5-HT and SP coexist within the broad area of raphe nuclei, it is likely that both molecules may be released not only from raphe obscurus, but also raphe magnus and raphe pallidus. Immunohistological evidence suggests that some substance $P$ in the pre-BötC appears to colocalize with glutamatergic, serotonergic, and also GABAergic presynaptic terminals (Ribeiro-da-Silva and Hökfelt, 2000; Liu et al., 2004).

While generally accepted that NK1 receptor activation is involved in breathing, its relative importance remained uncertain. Newborn NK1 receptor knock-out mice do not exhibit significant changes in the respiratory rhythm (Ptak et al., 2000). In light of the present study, these results are not surprising, since the other excitatory neuromodulators remained presumably active in these mutant mice and were thus able to compensate for the loss of NK1 activation.

Injections aimed at selectively destroying NK1 receptor-immunoreactive (NK1R-ir) neurons using SP-saporin (SPSAP) had dramatic breathing effects (Gray et al., 2001; Wang et al., 2003; McKay et al., 2005). But this approach lesions NK1R-ir neurons, which eliminates not only NK1R activation, but presumably also the very neurons that receive convergent noradrenergic and serotonergic inputs. Interestingly, when these animals fell asleep, they stopped breathing altogether (McKay et al., 2005; McKay and Feldman, 2008). Our results provide a possible explanation for this state dependency: during sleep, NE and 5-HT activation is low, thus rendering the network more sensitive to the loss of neuromodulatory drive.

Our studies may have also important clinical implications. For example, mutations of the Mafb gene in mice cause respiratory arrest at birth, and result in the loss of approximately onethird of the NK1-positive cells in the pre-BötC (Blanchi et al., 2003). Similar human mutations may be discovered that link respiratory insufficiencies and susceptibilities to sudden infant death syndrome (SIDS) and sleep apnea. In case of SIDS, there is

A

RM stimulation

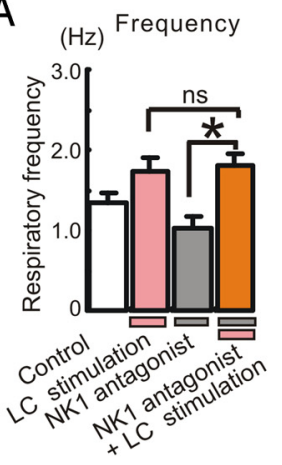

$\mathrm{B}$
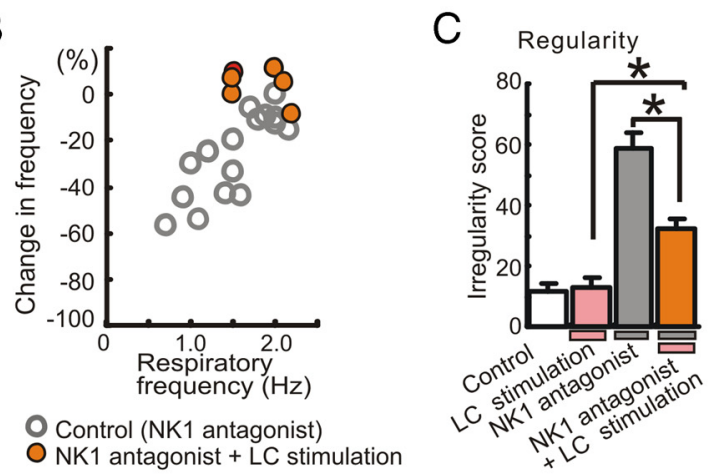

$D_{(\mathrm{Hz})}$ Frequency $\mathrm{E}$
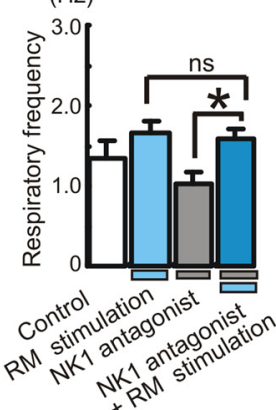

E



$\mathrm{F}$



LC and RM stimulation


Figure 8. Effects of electrical stimulation of $\mathrm{LC}$ and/or RM on the frequency and regularity changes caused by NK1 antagonists. $A, D, G$, The inhibitory effect of the NK1 antagonist on respiratory frequency is abolished by electrical stimulation of $L C\left(\boldsymbol{A}^{*}{ }^{*} p<\right.$ $0.05 ;$ ns, no significance; $n=6)$, RM ( $\boldsymbol{D},{ }^{*} p<0.05 ;$ ns, no significance; $\left.n=6\right)$, or both $\left(G,{ }^{*} p<0.05 ;\right.$ ns, no significance; $\left.n=5\right)$. $\boldsymbol{B}, \boldsymbol{E}, \boldsymbol{H}$, Scatter plots illustrating the relationship between percentage change in respiratory frequency (ordinate) and baseline respiratory frequency (abscissa) before manipulating the preparations. The ordinate reflects the percentage change in frequency compared to the control frequency (100\%) in any given preparation. Note that electrical stimulation of $\mathrm{LC}$ and/or RM significantly reduces the irregularity score caused by the NK1 antagonist, but does not fully recover the regularity when compared to control conditions $\left(\boldsymbol{C}, \boldsymbol{F}, \boldsymbol{I},{ }^{*} p<0.05\right)$.

increasing evidence for a role for 5-HT (Paterson et al., 2006; Rand et al., 2007; Broadbelt et al., 2009; Kinney et al., 2009; Duncan et al., 2010). SIDS (and also sleep apnea) occurs predominantly during sleep, when aminergic and presumably also SP levels are reduced. Only in such a reduced modulatory state is the respiratory network critically dependent on an individual neuromodulator, as suggested here for the dependency on SP. In the awake state, it is unlikely that a disruption of a single excitatory neuro- 
A
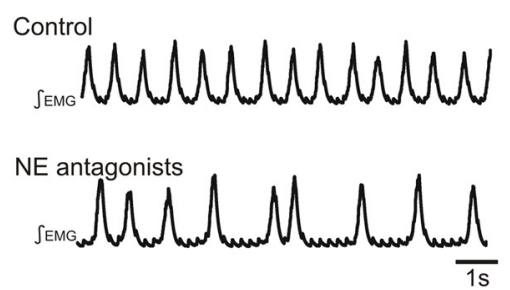

B

LC stimulation plus NE blockers

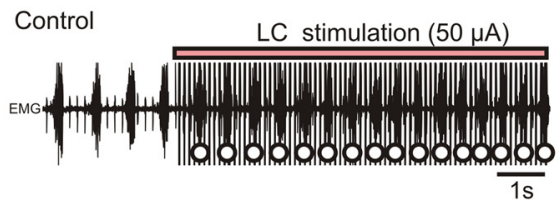

NE antagonists

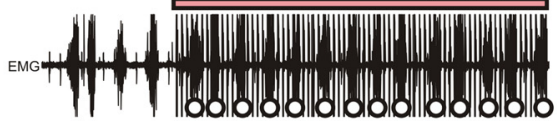

C



$\mathrm{F}$

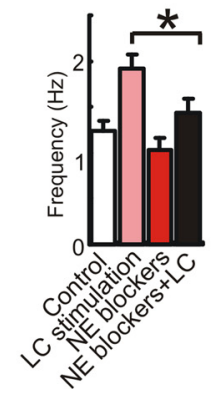

Figure 9. Electrical stimulation of $L C$ induces endogenous release of NE and acts on NE receptors presumably within the pre-BötC. $\boldsymbol{A}$, Integrated EMG activity obtained from intercostal muscle under control conditions (top trace) and following the injection of a cocktail of NE antagonists containing prazosin $(30 \mu \mathrm{M})$, yohimbine $(1 \mu \mathrm{M})$, and alprenolol (30 $\mu \mathrm{m}$, total $0.6 \mu \mathrm{l}$, bottom trace). $\boldsymbol{B}, \mathrm{EMG}$ activity recorded during $\mathrm{LC}$ stimulation under control conditions (top trace) and following the injection of the cocktail containing NE antagonists (bottom trace). $\boldsymbol{C}-\boldsymbol{E}$, Bar graphs illustrating the effects of NE antagonists on integrated respiratory amplitude $(\boldsymbol{C}, \mathrm{ns}, n=5)$, frequency $\left(\boldsymbol{D},{ }^{*} p<0.05\right)$, and regularity of respiratory frequency $\left(\boldsymbol{E},{ }^{*} p<0.05\right)$. $\boldsymbol{F}, \boldsymbol{G}$, Bar graphs illustrating that $L C$ stimulation (pink bars) affects only respiratory frequency $\left(\boldsymbol{F}_{,}^{*} p<0.05, n=5\right)$, but not the regularity of the frequency ( $\boldsymbol{G}$, irregularity score, ns) under control conditions (white bars) and following the injection of the cocktail containing NE antagonists (red bars).

modulator will have much of a critical effect, since the modulatory state is relatively high. This may explain why children that later died of SIDS have apparently no breathing problems during the day. Thus, understanding the convergence of different neuromodulators is not only an interesting basic scientific issue, but will also be important for gaining insights into the neurobiology of breathing disorders.

It is well established that gasping critically depends on persistent sodium-dependent pacemaker neurons. This was originally shown in vitro (Peña et al., 2004) and subsequently confirmed in vivo (Paton and St-John, 2007; Peña and Aguileta, 2007). However, whether gasping depends on a single neuromodulator (in this case 5-HT) as suggested by in vitro experiments (Tryba et al., 2006) or on multiple modulators as suggested by an in situ preparation (Toppin et al., 2007) remains unknown. Further studies will be necessary to investigate how the state dependency of these neuromodulatory systems is affected under hypoxic conditions both in vitro and in vivo. Moreover, it will also be important to unravel how gasping, sighs, and apneas are simultaneously controlled by neuropeptides (such as SP) and noradrenergic and serotonergic systems in the intact animal, and how they change during postnatal development (Peña et al., 2008), interesting questions that go beyond the scope of the present study.

Another interesting observation is that conditional $\mathrm{KO}$ mice for 5-HT exhibit dramatic respiratory disturbance and excessive mortality when lesioned in neonates (Ptak et al., 2009), while the same manipulation had much less dramatic effects in more mature mice (Ptak et al., 2009). This difference could be explained by the differential maturation of other modulatory systems (Murrin
E

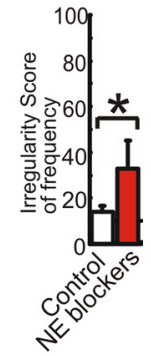

$\mathrm{G}$



et al., 2007) and/or the respiratory rhythm-generating network (Peña et al., 2008).

Thus, our study emphasizes the importance of considering the convergence of different excitatory neuromodulators when interpreting the outcome of gene knock-outs or when considering the consequences in a patient that is missing one critical neuromodulator. Patients may appear normal during wakefulness, but reveal irregularities at sleep, when modulatory tone is low.

\section{References}

Achard P, Zanella S, Rodriguez R, Hilaire G (2005) Perinatal maturation of the respiratory rhythm generator in mammals: from experimental results to computational simulation. Respir Physiol Neurobiol 149:17-27.

Barthe JY, Clarac F (1997) Modulation of the spinal network for locomotion by substance $\mathrm{P}$ in the neonatal rat. Exp Brain Res 115: 485-492.

Benavides DR, Quinn JJ, Zhong P, Hawasli AH, DiLeone RJ, Kansy JW, Olausson P, Yan Z, Taylor JR, Bibb JA (2007) Cdk5 modulates cocaine reward, motivation, and striatal neuron excitability. J Neurosci 27:12967-12976.

Ben-Mabrouk F, Tryba AK (2010) Substance P modulation of TRPC3/7 channels improves respiratory rhythm regularity and ICANdependent pacemaker activity. Eur J Neurosci 31:1219-1232.

Bernard R, Lydic R, Baghdoyan HA (2003) Hypocretin-1 causes $G$ protein activation and increases ACh release in rat pons. Eur J Neurosci 18:1775-1785.

Berridge CW, Waterhouse BD (2003) The locus coeruleus-noradrenergic system: modulation of behavioral state and state-dependent cognitive processes. Brain Res Brain Res Rev 42:33-84.

Bianchi AL, Denavit-Saubié M, Champagnat J (1995) Central control of breathing in mammals: neuronal circuitry, membrane properties, and neurotransmitters. Physiol Rev 75:1-45.

Birmingham JT, Billimoria CP, DeKlotz TR, Stewart RA, Marder E (2003) Differential and history-dependent modulation of a stretch receptor in the stomatogastric system of the crab, Cancer borealis. J Neurophysiol 90:3608-3616.

Blanchi B, Kelly LM, Viemari JC, Lafon I, Burnet H, Bévengut M, Tillmanns S, Daniel L, Graf T, Hilaire G, Sieweke MH (2003) MafB deficiency causes defective respiratory rhythmogenesis and fatal central apnea at birth. Nat Neurosci 6:1091-1100.

Broadbelt KG, Barger MA, Paterson DS, Holm IA, Haas EA, Krous HF, Kinney HC, Markianos K, Beggs AH (2009) Serotonin-related FEV gene variant in the sudden infant death syndrome is a common polymorphism in the African-American population. Pediatr Res 66:631-635.

Brown RE, Stevens DR, Haas HL (2001) The physiology of brain histamine. Prog Neurobiol 63:637-672.

Colin I, Blondeau C, Baude A (2002) Neurokinin release in the rat nucleus of the solitary tract via NMDA and AMPA receptors. Neuroscience 115:1023-1033.

Crowder EA, Saha MS, Pace RW, Zhang H, Prestwich GD, Del Negro CA (2007) Phosphatidylinositol 4,5-bisphosphate regulates inspiratory burst activity in the neonatal mouse preBotzinger complex. J Physiol 582:1047-1058.

Del Negro CA, Koshiya N, Butera RJ Jr, Smith JC (2002) Persistent sodium current, membrane properties and bursting behavior of pre-botzinger complex inspiratory neurons in vitro. J Neurophysiol 88:2242-2250.

Dias MB, Li A, Nattie E (2010) The orexin receptor 1 (OX(1)R) in the rostral medullary raphe contributes to the hypercapnic chemoreflex in wakeful- 
ness, during the active period of the diurnal cycle. Respir Physiol Neurobiol 170:96-102.

Djukic B, Casper KB, Philpot BD, Chin LS, McCarthy KD (2007) Conditional knock-out of Kir4.1 leads to glial membrane depolarization, inhibition of potassium and glutamate uptake, and enhanced short-term synaptic potentiation. J Neurosci 27:11354-11365.

Doi A, Ramirez JM (2008) Neuromodulation and the orchestration of the respiratory rhythm. Respir Physiol Neurobiol 164:96104.

Dringenberg HC, Vanderwolf CH (1998) Involvement of direct and indirect pathways in electrocorticographic activation. Neurosci Biobehav Rev 22:243-257.

Duangdao DM, Clark SD, Okamura N, Reinscheid RK (2009) Behavioral phenotyping of neuropeptide $S$ receptor knockout mice. Behav Brain Res 205:1-9.

Duncan JR, Paterson DS, Hoffman JM, Mokler DJ, Borenstein NS, Belliveau RA, Krous HF, Haas EA, Stanley C, Nattie EE, Trachtenberg FL, Kinney HC (2010) Brainstem serotonergic deficiency in sudden infant death syndrome. JAMA 303:430-437.

Ellenberger HH, Smith FM (1999) Sulfated cholecystokinin octapeptide in the rat: pontomedullary distribution and modulation of the respiratory pattern. Can J Physiol Pharmacol 77:490-504.

Fadok JP, Dickerson TM, Palmiter RD (2009) Dopamine is necessary for cue-dependent fear conditioning. J Neurosci 29:11089-11097.

Feldman JL, Del Negro CA (2006) Looking for inspiration: new perspectives on respiratory rhythm. Nat Rev Neurosci 7:232-242.

Fong AY, Potts JT (2008) Neurokinin-1 receptors modulate the excitability of expiratory neurons in the ventral respiratory group. J Neurophysiol 99:900-914.

Grashow R, Brookings T, Marder E (2009) Reliable neuromodulation from circuits with variable underlying structure. Proc Natl Acad Sci U S A 106:11742-11746.

Gray PA, Rekling JC, Bocchiaro CM, Feldman JL (1999) Modulation of respiratory frequency by peptidergic input to rhythmogenic neurons in the preBotzinger complex. Science 286:1566-1568.

Gray PA, Janczewski WA, Mellen N, McCrimmon DR, Feldman JL (2001) Normal breathing requires preBotzinger complex neurokinin-1 receptorexpressing neurons. Nat Neurosci 4:927-930.

Guyenet PG, Sevigny CP, Weston MC, Stornetta RL (2002) Neurokinin-1 receptor-expressing cells of the ventral respiratory group are functionally heterogeneous and predominantly glutamatergic. J Neurosci 22: 3806-3816.

Hayes JA, Del Negro CA (2007) Neurokinin receptor-expressing prebotzinger complex neurons in neonatal mice studied in vitro. J Neurophysiol 97:4215-4224.

Higuchi H, Niki T, Shiiya T (2008) Feeding behavior and gene expression of appetite-related neuropeptides in mice lacking for neuropeptide Y Y5 receptor subclass. World J Gastroenterol 14:6312-6317.

Hilaire G, Burnet H, Ptak K, Sieweke M, Blanchi B, De Felipe C, Hunt S, Monteau R (2003) Deletion of tachykinin NK1 receptor gene in mice does not alter respiratory network maturation but alters respiratory responses to hypoxia. Adv Exp Med Biol 536:497-504.

Hilaire G, Viemari JC, Coulon P, Simonneau M, Bévengut M (2004) Modulation of the respiratory rhythm generator by the pontine noradrenergic A5 and A6 groups in rodents. Respir Physiol Neurobiol 143:187-197.

Hodges MR, Richerson GB (2008) Contributions of 5-HT neurons to respiratory control: neuromodulatory and trophic effects. Respir Physiol Neurobiol 164:222-232.

Hodges MR, Wehner M, Aungst J, Smith JC, Richerson GB (2009) Transgenic mice lacking serotonin neurons have severe apnea and high mortality during development. J Neurosci 29:10341-10349.

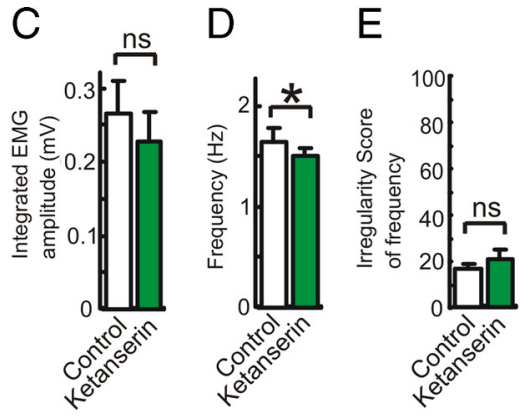

$\mathrm{F}$

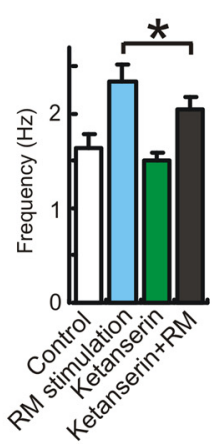

G



Hökfelt T, Arvidsson U, Cullheim S, Millhorn D, Nicholas AP, Pieribone V, Seroogy K, Ulfhake B (2000) Multiple messengers in descending serotonin neurons: localization and functional implications. J Chem Neuroanat 18:75-86.

Jansen F, Heiming RS, Lewejohann L, Touma C, Palme R, Schmitt A, Lesch KP, Sachser N (2010) Modulation of behavioural profile and stress response by 5-HTT genotype and social experience in adulthood. Behav Brain Res 207:21-29.

Kinney HC, Richerson GB, Dymecki SM, Darnall RA, Nattie EE (2009) The brainstem and serotonin in the sudden infant death syndrome. Annu Rev Pathol 4:517-550.

Koizumi H, Smerin SE, Yamanishi T, Moorjani BR, Zhang R, Smith JC (2010) TASK channels contribute to the $\mathrm{K}^{+}$-dominated leak current regulating respiratory rhythm generation in vitro. J Neurosci 30:4273-4284.

Kvachnina E, Liu G, Dityatev A, Renner U, Dumuis A, Richter DW, Dityateva G, Schachner M, Voyno-Yasenetskaya TA, Ponimaskin EG (2005) $5-\mathrm{HT}_{7}$ receptor is coupled to $\mathrm{G} \alpha$ subunits of heterotrimeric G12-protein to regulate gene transcription and neuronal morphology. J Neurosci 25:7821-7830.

Léger L, Gay N, Cespuglio R (2002) Neurokinin NK1- and NK3immunoreactive neurons in serotonergic cell groups in the rat brain. Neurosci Lett 323:146-150.

Lieske SP, Thoby-Brisson M, Telgkamp P, Ramirez JM (2000) Reconfiguration of the neural network controlling multiple breathing patterns: eupnea, sighs and gasps. Nat Neurosci 3:600-607.

Liu YY, Wong-Riley MT, Liu JP, Wei XY, Jia Y, Liu HL, Fujiyama F, Ju G (2004) Substance P and enkephalinergic synapses onto neurokinin-1 receptor-immunoreactive neurons in the pre-Botzinger complex of rats. Eur J Neurosci 19:65-75.

Lu B, Su Y, Das S, Wang H, Wang Y, Liu J, Ren D (2009) Peptide neurotransmitters activate a cation channel complex of NALCN and UNC-80. Nature 457:741-744.

Manzke T, Guenther U, Ponimaskin EG, Haller M, Dutschmann M, Schwar- 
A
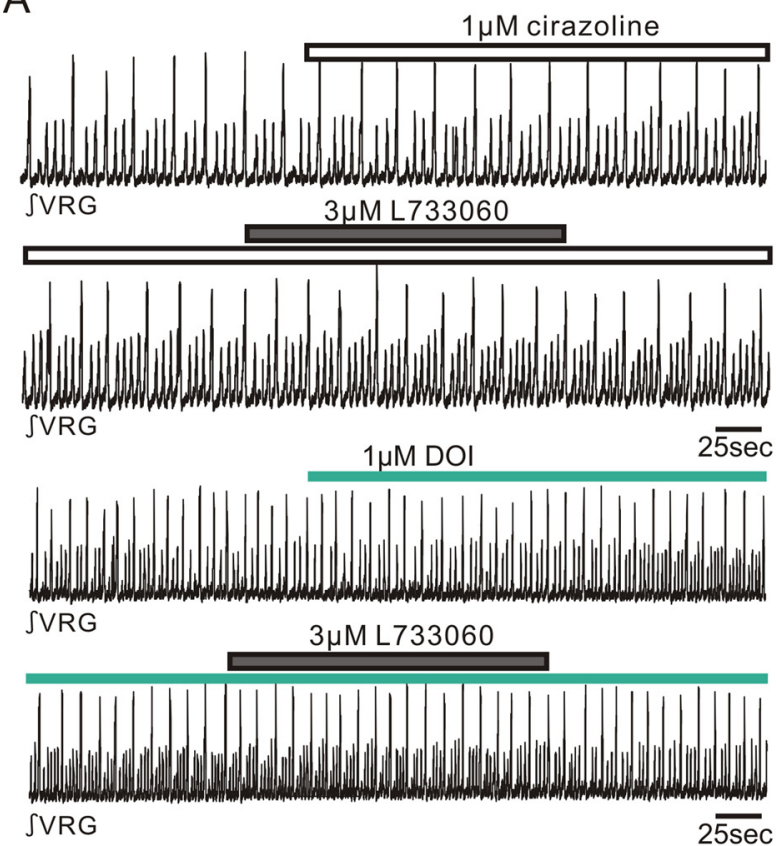

B
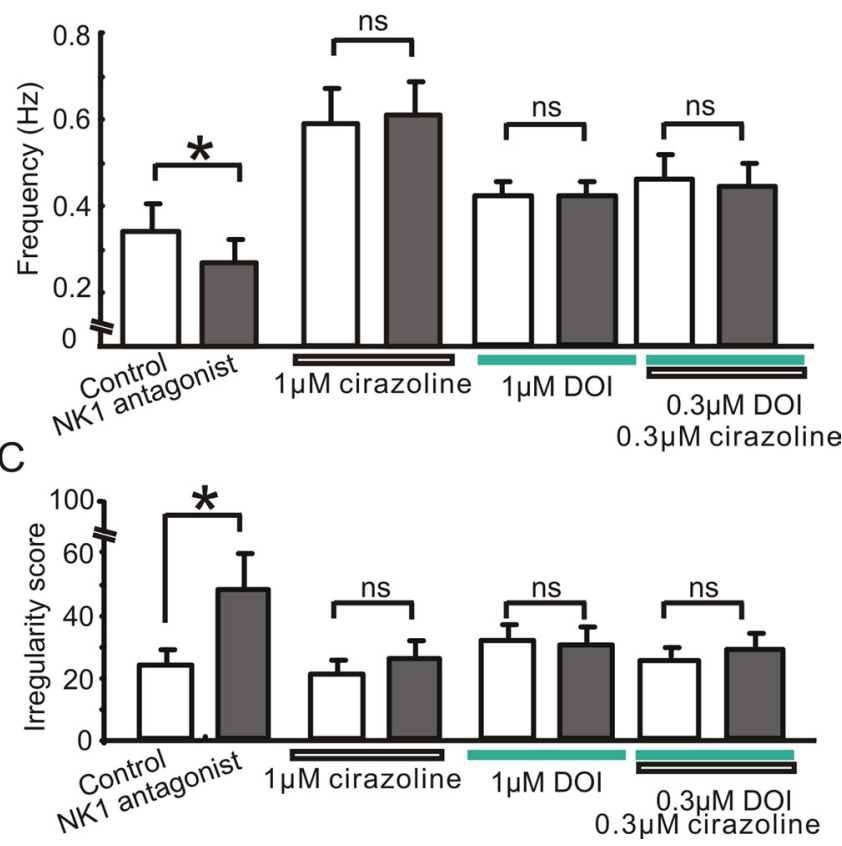

Figure 11. Interactions between NK1, $\alpha 1 \mathrm{NE}$, and 5-HT2 receptors in slice preparations. $A$, Integrated activity obtained from population activity recorded extracellularly from the surface of a portion of the VRG containing the pre-BötC. Note the slice exhibited spontaneously normal respiratory activity (small upward deflections) as well as large amplitude deflections that reflect fictive sigh activity (Lieske et al., 2000). Integrated activity was recorded in the presence of the $\alpha 1 \mathrm{NE}$ agonist cirazoline before (top trace, white bar) and during the application of the NK1 antagonist L733060 (second trace, gray bar), as well as in the presence of the 5-HT2 agonist DOl before (third trace, green bar) and during the application of the NK1 antagonist L733060 (fourth trace, gray bar). B, C, Bar graphs quantifying the effects on frequency $(\boldsymbol{B})$ and irregularity score $(\boldsymbol{C})$ under the conditions before (white bars) and during the application of the NK1 antagonist ( $3 \mu \mathrm{m} \mathrm{L733060;}$; black bars). The bar graphs from left to right illustrate the effects of the NK1 antagonist under control conditions, in the presence of $1 \mu \mathrm{m}$ cirazoline, $1 \mu \mathrm{m} \mathrm{DOl,} \mathrm{and} 0.3 \mu \mathrm{m} \mathrm{DOI} \mathrm{plus} 0.3 \mu \mathrm{m}$ cirazoline (bar graphs from left to right, ${ }^{*} p<0.05, n=5$ ).

zacher S, Richter DW (2003) 5-HT4(a) receptors avert opioid-induced breathing depression without loss of analgesia. Science 301:226-229.

Mason P (2001) Contributions of the medullary raphe and ventromedial reticular region to pain modulation and other homeostatic functions. Annu Rev Neurosci 24:737-777.

McKay LC, Feldman JL (2008) Unilateral ablation of pre-Botzinger complex disrupts breathing during sleep but not wakefulness. Am J Respir Crit Care Med 178:89-95.

McKay LC, Janczewski WA, Feldman JL (2005) Sleep-disordered breathing after targeted ablation of preBotzinger complex neurons. Nat Neurosci 8:1142-1144.

Morgado-Valle C, Feldman JL (2004) Depletion of substance P and glutamate by capsaicin blocks respiratory rhythm in neonatal rat in vitro. J Physiol 555:783-792.

Murase K, Randic M, Shirasaki T, Nakagawa T, Akaike N (1990) Serotonin suppresses $\mathrm{N}$-methyl-D-aspartate responses in acutely isolated spinal dorsal horn neurons of the rat. Brain Res 525:84-91.

Murrin LC, Sanders JD, Bylund DB (2007) Comparison of the maturation of the adrenergic and serotonergic neurotransmitter systems in the brain: implications for differential drug effects on juveniles and adults. Biochem Pharmacol 73:1225-1236.

Nadim F, Brezina V, Destexhe A, Linster C (2008) State dependence of network output: modeling and experiments. J Neurosci 28:11806-11813.

Nusbaum MP (2002) Regulating peptidergic modulation of rhythmically active neural circuits. Brain Behav Evol 60:378-387.

Onimaru H, Homma I (2003) A novel functional neuron group for respiratory rhythm generation in the ventral medulla. J Neurosci 23:1478-1486.

Ortinski PI, Turner JR, Barberis A, Motamedi G, Yasuda RP, Wolfe BB, Kellar KJ, Vicini S (2006) Deletion of the $\mathrm{GABA}_{\mathrm{A}}$ receptor $\alpha 1$ subunit increases tonic $\mathrm{GABA}_{\mathrm{A}}$ receptor current: a role for GABA uptake transporters. J Neurosci 26:9323-9331.

Pagnotta SE, Lape R, Quitadamo C, Nistri A (2005) Pre- and postsynaptic modulation of glycinergic and gabaergic transmission by muscarinic receptors on rat hypoglossal motoneurons in vitro. Neuroscience 130:783-795.

Paterson DS, Trachtenberg FL, Thompson EG, Belliveau RA, Beggs AH,
Darnall R, Chadwick AE, Krous HF, Kinney HC (2006) Multiple serotonergic brainstem abnormalities in sudden infant death syndrome. JAMA 296:2124-2132.

Paterson DS, Hilaire G, Weese-Mayer DE (2009) Medullary serotonin defects and respiratory dysfunction in sudden infant death syndrome. Respir Physiol Neurobiol 168:133-143.

Paton JF, St-John WM (2007) Counterpoint: Medullary pacemaker neurons are essential for gasping, but not eupnea, in mammals. J Appl Physiol 103:718-720; discussion 721-722.

Peck JH, Gaier E, Stevens E, Repicky S, Harris-Warrick RM (2006) Amine modulation of Ih in a small neural network. J Neurophysiol 96:29312940.

Peña F, Aguileta MA (2007) Effects of riluzole and flufenamic acid on eupnea and gasping of neonatal mice in vivo. Neurosci Lett 415:288-293.

Peña F, Ramirez JM (2002) Endogenous activation of serotonin-2A receptors is required for respiratory rhythm generation in vitro. J Neurosci 22:11055-11064

Peña F, Ramirez JM (2004) Substance P-mediated modulation of pacemaker properties in the mammalian respiratory network. J Neurosci 24:7549-7556.

Peña F, Parkis MA, Tryba AK, Ramirez JM (2004) Differential contribution of pacemaker properties to the generation of respiratory rhythms during normoxia and hypoxia. Neuron 43:105-117.

Peña F, Meza-Andrade R, Páez-Zayas V, González-Marín MC (2008) Gasping generation in developing Swiss-Webster mice in vitro and in vivo. Neurochem Res 33:1492-1500.

Ptak K, Hunt SP, Monteau R (2000) Substance P and central respiratory activity: a comparative in vitro study in NK1 receptor knockout and wildtype mice. Pflugers Arch 440:446-451.

Ptak K, Burnet H, Blanchi B, Sieweke M, De Felipe C, Hunt SP, Monteau R, Hilaire G (2002) The murine neurokinin NK1 receptor gene contributes to the adult hypoxic facilitation of ventilation. Eur J Neurosci 16:2245-2252.

Ptak K, Yamanishi T, Aungst J, Milescu LS, Zhang R, Richerson GB, Smith JC (2009) Raphe neurons stimulate respiratory circuit activity by multiple 
mechanisms via endogenously released serotonin and substance P. J Neurosci 29:3720-3737.

Ramirez JM, Quellmalz UJ, Richter DW (1996) Postnatal changes in the mammalian respiratory network as revealed by the transverse brainstem slice of mice. J Physiol 491:799-812.

Ramirez JM, Tryba AK, Peña F (2004) Pacemaker neurons and neuronal networks: an integrative view. Curr Opin Neurobiol 14:665-674.

Rand CM, Berry-Kravis EM, Zhou L, Fan W, Weese-Mayer DE (2007) Sudden infant death syndrome: rare mutation in the serotonin system FEV gene. Pediatr Res 62:180-182.

Ribeiro-da-Silva A, Hökfelt T (2000) Neuroanatomical localisation of substance $\mathrm{P}$ in the CNS and sensory neurons. Neuropeptides 34:256-271.

Shao XM, Feldman JL (2005) Cholinergic neurotransmission in the preBotzinger complex modulates excitability of inspiratory neurons and regulates respiratory rhythm. Neuroscience 130:1069-1081.

Smith JC, Ellenberger HH, Ballanyi K, Richter DW, Feldman JL (1991) PreBotzinger complex: a brainstem region that may generate respiratory rhythm in mammals. Science 254:726-729.

Smith JC, Abdala AP, Koizumi H, Rybak IA, Paton JF (2007) Spatial and functional architecture of the mammalian brain stem respiratory network: a hierarchy of three oscillatory mechanisms. J Neurophysiol 98:3370-3387.

Stein W, DeLong ND, Wood DE, Nusbaum MP (2007) Divergent cotransmitter actions underlie motor pattern activation by a modulatory projection neuron. Eur J Neurosci 26:1148-1165.

Swensen AM, Bean BP (2005) Robustness of burst firing in dissociated Purkinje neurons with acute or long-term reductions in sodium conductance. J Neurosci 25:3509-3520.

Tan W, Janczewski WA, Yang P, Shao XM, Callaway EM, Feldman JL (2008) Silencing preBotzinger complex somatostatin-expressing neurons induces persistent apnea in awake rat. Nat Neurosci 11:538-540.

Tao R, Ma Z, McKenna JT, Thakkar MM, Winston S, Strecker RE, McCarley RW (2006) Differential effect of orexins (hypocretins) on serotonin release in the dorsal and median raphe nuclei of freely behaving rats. Neuroscience 141:1101-1105.

Telgkamp P, Ramirez JM (1999) Differential responses of respiratory nuclei to anoxia in rhythmic brain stem slices of mice. J Neurophysiol 82:2163-2170.

Telgkamp P, Cao YQ, Basbaum AI, Ramirez JM (2002) Long-term deprivation of substance P in PPT-A mutant mice alters the anoxic response of the isolated respiratory network. J Neurophysiol 88:206-213.
Thirumalai V, Marder E (2002) Colocalized neuropeptides activate a central pattern generator by acting on different circuit targets. J Neurosci 22:1874-1882.

Thoby-Brisson M, Simmers J (1998) Neuromodulatory inputs maintain expression of a lobster motor pattern-generating network in a modulationdependent state: evidence from long-term decentralization in vitro. J Neurosci 18:2212-2225.

Toppin VA, Harris MB, Kober AM, Leiter JC, St-John WM (2007) Persistence of eupnea and gasping following blockade of both serotonin type 1 and 2 receptors in the in situ juvenile rat preparation. J Appl Physiol 103:220-227.

Tryba AK, Peña F, Ramirez JM (2003) Stabilization of bursting in respiratory pacemaker neurons. J Neurosci 23:3538-3546.

Tryba AK, Peña F, Ramirez JM (2006) Gasping activity in vitro: a rhythm dependent on $5-\mathrm{HT}_{2 \mathrm{~A}}$ receptors. J Neurosci 26:2623-2634.

Ursin R (2002) Serotonin and sleep. Sleep Med Rev 6:55-69.

VanderHorst VG, Ulfhake B (2006) The organization of the brainstem and spinal cord of the mouse: relationships between monoaminergic, cholinergic, and spinal projection systems. J Chem Neuroanat 31:2-36.

Viemari JC, Ramirez JM (2006) Norepinephrine differentially modulates different types of respiratory pacemaker and nonpacemaker neurons. J Neurophysiol 95:2070-2082.

Wang H, Weston MC, McQuiston TJ, Stornetta RL, Guyenet PG (2003) Neurokinin-1 receptor-expressing cells regulate depressor region of rat ventrolateral medulla. Am J Physiol Heart Circ Physiol 285:H2757H2769.

Ward SJ, Walker EA (2009) Sex and cannabinoid CB1 genotype differentiate palatable food and cocaine self-administration behaviors in mice. Behav Pharmacol 20:605-613.

Wehr M, Hostick U, Kyweriga M, Tan A, Weible AP, Wu H, Wu W, Callaway EM, Kentros C (2009) Transgenic silencing of neurons in the mammalian brain by expression of the allatostatin receptor (AlstR). J Neurophysiol 102:2554-2562.

Zec N, Kinney HC (2003) Anatomic relationships of the human nucleus of the solitary tract in the medulla oblongata: a DiI labeling study. Auton Neurosci 105:131-144.

Zhou Y, Won J, Karlsson MG, Zhou M, Rogerson T, Balaji J, Neve R, Poirazi P, Silva AJ (2009) CREB regulates excitability and the allocation of memory to subsets of neurons in the amygdala. Nat Neurosci 12:14381443. 